\title{
Regional thrombolysis in lower limb ischemia: new pharmacological and non- pharmacological aspects
}

\author{
Raymond Verhaeghe \\ Center for Molecular and Vascular Biology, University of Leuven, Belgium
}

\section{Acknowledgement}

The author holds the J. Vromans-Sautié chair of preventive cardiovascular medicine

\section{Summary}

Regional thrombolytic therapy for arterial occlusion of the limbs uses several catheter-guided techniques and various infusion methods and therapeutic schemes. There is no definite proof of superiority of any agent in terms of efficacy and safety. A meta-analysis of randomized trials comparing surgery to thrombolysis in leg ischemia shows no significant difference in major amputation and mortality between these two management options. Major bleeding is the main complication. Recent developments include the introduction of new thrombolytic agents, associated infusion of glycoprotein IIb-Illa blockers and use of ultrasound to disrupt thrombi or facilitate thrombolysis.

Copyright @ 2002 S. Karger AG. Basel

Systemic thrombolysis for an acute occlusion of limb arteries as practiced in the 1960's and 1970's has been almost completely abandoned and replaced by regional thrombolysis via an intra-arterial catheter. Regional thrombolysis was launched in the late 70's, but it took a decade before it became accepted as an established treatment modality.

\section{KARGER \\ Fax +41613061234 \\ E-Mail karger@karger.ch}

www.Karger.com (c) 2002 S. Karger AG. Basel

$1424-8832 / 02 / 0326-0299 \$ 18.50 / 0$

\section{Techniques in regional thrombolysis (Table 1)}

Continuous infusion of the thrombolytic agent with the aid of a steady-flow infusion pump is the most popular technique. The catheter tip is advanced into the thrombus to render the thrombolysis optimally selective and efficacious. Frequently, the thrombus is initially "laced" over its entire length with a bolus of thrombolytic agent while withdrawing a thin catheter from the distal to the proximal part of the thrombus, the aim being to reduce the lysis time. Thereafter, the infusion rate is either constant or periodically tapered with the highest dose given at the start of the infusion. Progression of clot lysis is followed by fluoroscopy or angiography with an interval of several hours and the catheter is repositioned as needed.

Reduction of lysis time is also the aim of "pulse-spray" repeated forceful injection and "pulse(d)-spray pharmacomechanical thrombolysis". This latter device combines mechanical thrombus disruption caused by brief high pressure pulsed

Table 1. techniques in catheter-thrombolysis

\footnotetext{
- stepwise infiltration

- continuous infusion

- graded infusion

- accelerated thrombolysis lacing of the thrombus pulse spray infusion pulse(d)-spray pharmacomechanical thrombolysis - enclosed thrombolysis
}

R. Verhaeghe, M.D

Center for Molecular and Vascular Biology

Campus Gasthuisberg

Herestraat 49 B-3000 Leuven (Belgium)

Tel: (32-16)-34.34.91 Fax: (32-16)-34.34.93

e-mail: raymond.verhaeghe@uz.kuleuven.ac.be 
injections of thrombolytic agent throughout the thrombus and pharmacological fibrinolysis. There is however doubt whether this technique is superior to the conventional regional infusion [1]. "Enclosed thrombolysis" refers to the infusion of a thrombolytic agent into the space between the two balloons of a double balloon catheter: one balloon, at the tip of a catheter, is placed distally to the occluding thrombus whereas the second balloon is proximally to the thrombus.

\section{Choice of thrombolytic agent}

In the early days of regional thrombolysis, streptokinase (SK) was the most widely used agent. Later urokinase (UK) and recombinant tissue-type plasminogen activator (rt-PA) superseded SK as preferred agents, but sales of urokinase was suspended in the United States in 1998. For UK, dosage varies but schemes with progressive tapering are popular. With rt-PA, the dosage schemes vary from $0.025 \mathrm{mg} / \mathrm{kg} / \mathrm{h}$ to $0.1 \mathrm{mg} / \mathrm{kg} / \mathrm{h}$ and from $0.25 \mathrm{mg} / \mathrm{h}$ to $10 \mathrm{mg} / \mathrm{h}$, but there is no obvious benefit from using the higher doses. Table 2 lists "acceptable" dosage regimens for regional thrombolysis.

Only a few randomized studies compared two thrombolytic agents directly. An open trial compared intra-arterial SK to intra-arterial and intravenous rt-PA in 60 patients with recent onset or deterioration of limb ischaemia: initial angiographic success was superior with intra-arterial rt-PA $(100 \%)$ than with intra-arterial SK $(80 \% ; \mathrm{p}<0.04)$ or intravenous rt-PA $(45 \%$ $\mathrm{p}<0.01$ ), the 30 days limb salvage rate being 80,60 and $45 \%$, respectively [2]. Another open randomized trial on 32 patients showed significantly faster lysis than with urokinase, but the 30 days success rate was similar [3]. In the Surgery versus Thrombolysis for Ischemia of the Lower Extremity (STILE) study, a randomized but open comparison of rt-PA and urokinase showed similar efficacy and safety of the two drugs [4]. Thus there is at present no scientific proof of superiority of any

Table 2. Commonly used dosage schemes in catheter thrombolysis

\begin{tabular}{|c|c|c|}
\hline agent & infusion & initial "lacing" dose \\
\hline streptokinase & $\begin{array}{l}5000 \mathrm{U} / \mathrm{h} \\
\text { continuous infusion }\end{array}$ & \\
\hline \multirow[t]{2}{*}{ urokinase } & $\begin{array}{l}4000 \mathrm{U} / \mathrm{min} \\
\text { to antegrade flow }\end{array}$ & 120,000 to $240,000 \mathrm{U}$ \\
\hline & $\begin{array}{l}1000 \mathrm{U} / \mathrm{min} \\
\text { to complete lysis }\end{array}$ & \\
\hline alteplase (rt-PA) & $\begin{array}{l}\text { either } 1 \mathrm{mg} / \mathrm{h} \\
\text { or } 0.05 \mathrm{mg} / \mathrm{kg} / \mathrm{h} \\
\text { continuous infusion }\end{array}$ & $\begin{array}{l}5 \mathrm{mg} \text { (may be repeated } \\
\text { twice, at } 5-10 \mathrm{~min} \\
\text { intervals) }\end{array}$ \\
\hline reteplase & $0.5-2 \mathrm{U} / \mathrm{h}$ & \\
\hline
\end{tabular}

agent for peripheral thrombolysis in terms of efficacy and safety.

A few studies randomized patients to thrombolysis or to surgical intervention [4-8]; they were recently meta-analyzed [9]. No significant difference was found between thrombolysis in terms of mortality and major amputation. Subgroup analysis suggested that recent occlusions and occluded bypass grafts may benefit from thrombolysis, whereas surgery is the preferred treatment for occlusions of greater than 14 days, particularly in native vessels. The results of this meta-analysis largely corroborate the recommendations forwarded by an expert group in a consensus document on the thrombolytic management of lower limb arterial occlusion [10].

\section{Complications of regional thrombolysis}

Problems with regional thrombolysis in leg ischemia are requirement of proper catheter placement, angiographic monitoring of progression, long duration of treatment and the need for subsequent endovascular or surgical repair of underlying causative lesions.

Severe systemic or intracranial bleeding is the most significant clinical risk associated with any thrombolytic therapy. This feared complication of all thrombolytic agents also occurs with fibrin specific thrombolytic agents and may be due to lysis of a pre-existing haemostatic plug, depletion of fibrinogen, loss of vascular integrity (e.g. puncture) and concomitant or continued anticoagulant treatment.

In descriptive series, the risk of haemorrhagic stroke, of major and of minor bleeding averages 1-2, 5-10 and 10-20\%, respectively. In three American prospective randomized studies which compared thrombolysis to surgery, the intracranial bleeding rate was $2.1 \%$ (TOPAS-I), $1.2 \%$ (STILE) and $1.6 \%$ (TOPAS-II) [4, 7, 8]. In the STILE-trial, no difference was found in bleeding complications between alteplase and urokinase [7]. In the meta-analysis, the aggregate odds ratio for major bleeding showed an almost 3-fold increased risk with thrombolysis [9]. Most bleeding during catheter thrombolysis occurs at sites of venous or arterial puncture. Pericatheter bleeding is particularly common, typically delayed in onset and probably multifactorial in origin. Fortunately, local bleeding is usually minor and controlled with prolonged local pressure. By contrast, bleeding into the retroperitoneal space from inadvertent posterior wall puncture may go undetected until hypotension develops.

The use of thrombolytic agents may cause cleavage of thrombus and distal embolisation of partially lysed fragments. Approximately $10-15 \%$ of limbs undergoing intra-arterial thrombolysis develop distal embolism or extension of thrombus during the procedure. These are usually of little clinical consequence and can be treated by continuing the thrombolysis. Acute deterioration of the limb due to increasing ischemia 
may require thrombus aspiration or operative intervention if the clinical condition does not improve quickly with continued thrombolysis

\section{New pharmacological developments}

Clinical studies in leg arterial occlusion have been reported for a few newly developed thrombolytic agents: recombinant human urokinase [4, 8], recombinant pro-urokinase [11], recombinant staphylokinase [12-13] and reteplase [14, 15].

The TOPAS (Thrombolysis Or Peripheral Arterial Surgery) investigators compared prospectively recombinant urokinase versus surgery in acute arterial occlusion (up to 14 days). Phase I of the TOPAS-trial compared 3 dosage schemes of recombinant UK to operative intervention in 213 patients with acute lower extremity ischemia: 240,000 IU/h for 4 hours and then $120,000 \mathrm{IU} / \mathrm{h}$ to a maximum of 48 hours appeared the most appropriate regimen, maximizing lytic efficacy $(71 \%)$ against bleeding risk (2\%) [4]. This optimal dosage regimen was next tested in a large multicenter trial on 544 patients. Amputation-free survival rates in the urokinase group were $71.8 \%$ at 6 months and $65.0 \%$ at one year, as compared with respective rates of $74.8 \%$ and $69.9 \%$ in the surgery group; these differences between the two groups are not significant. Thrombolysis reduced the need for open surgical procedures (315 versus 551 at 6 months) without increased risk of amputation or death [8]. In an analysis of outcome determinants, the length of the occlusion appeared to predict whether a patient is best served with thrombolysis or operative intervention: longer occlusions responded best with an initial thrombolytic strategy [16].

The PURPOSE trial compared 3 doses of recombinant prourokinase to tissue culture urokinase with complete lysis as primary endpoint: the highest lysis rate was obtained with the highest dose tested $(8 \mathrm{mg} / \mathrm{h}$ for 8 hours, then $0.5 \mathrm{mg} / \mathrm{h})$, at the expense of a slightly increased frequency of bleeding and of decrement in fibrinogen level [11].

Recombinant staphylokinase (wild type or variants) produced complete revascularization in $158 / 191$ patients with a one-year amputation-free survival of $84 \%$. Major hemorrhage occurred in 23 patients (12\%), of whom 4 had a fatal intracranial bleeding. Fibrinogen levels remained unaffected during treatment [13].

Reteplase, a non-glycosylated mutant of alteplase, was tested in a few small series: dosages of 0.5 up to $2 \mathrm{U} / \mathrm{h}$ produced thrombus dissolution rates and bleeding rates which appear comparable to published data with other thrombolytic agents but a direct comparison is not available [14, 15].

A new approach is the use of the glycoprotein IIb-IIIa antagonist abciximab as adjuvant therapy to thrombolysis. The hope is to improve lytic efficacy and clinical outcome. If lysis of thrombus in a vessel is a dynamic phenomenon with formation of new clot while the occluding thrombus is being dissolved, inhibition of thrombosis may speed up the lytic process and reduce the complication risk. A pilot trial randomized 70 patients to urokinase plus abciximab or to urokinase plus placebo. At 90 days amputation-free survival was $96 \%$ in the urokinase-abciximab group versus $80 \%$ in the urokinase-placebo group. Thrombolysis occurred faster in the former group, but the rate of non-fatal major bleeding was higher as well [17]. In a small series, combined treatment with reteplase and abciximab produced complete lysis in 14 out of 15 patients $(93 \%)$ [18].

In the early days of thrombolytic therapy, systemic infusion of plasmin was evaluated as a direct fibrinolytic enzyme with potential clinical interest but quickly abandoned. There is renewed interest in the intra-thrombus application of plasmin: it is expected to produce locally equivalent clot lysis as plasminogen activators whereas inactivation of plasmin in the flowing blood may reduce the bleeding risk [19]. Microplasmin, a "reduced-size" derivative of plasmin, is a promising development to solve production problems of stable plasmin in therapeutic amounts [20].

\section{Non-pharmacological aspects}

Percutaneous aspiration of clot through a large bore catheter is an alternative to open surgery or to pharmacological thrombolysis for patients with acute limb ischemia due to embolic arterial occlusion. Over the last two decades, a number of devices for percutaneous mechanical thrombectomy have been promoted. They intend to facilitate thrombus removal (in comparison with simple aspiration) and use therefore various mechanisms or combinations of mechanisms; their efficacy is counterbalanced by a propensity for distal embolization. In addition, wall-contact devices may cause vessel wall damage and thus augment the risk of rethrombosis. Published experience in limb ischemia is limited: most frequently percutaneous techniques are being used for debulking of thrombus mass as an adjunct to pharmacological thrombolysis [21].

A new approach is the use of ultrasound delivered either transcutaneously or via catheter. The application of high intensities ultrasound appears to disrupt thrombus and microbubble echocontrast agents may augment this effect; lower intensity ultrasound rather enhances pharmacological thrombolysis induced by plasminogen activators [22]. A few small clinical studies have shown the ability of endovascularly delivered high intensity ultrasound to recanalize occluded vessel segments; problems are heating of the catheter and injury and risk of perforation of the vessel wall. 


\section{References}

1. Kandarpa K, Chopra PS, Arung JE, Meyerovitz MF, Goldhaber SZ. Intra-arterial thrombolysis of lower extremity occlusion: prospective randomized comparison of forced periodic infusion and conventional slow continuous infusion. Radiology 1993; 188: 861867.

2. Berridge DC, Gregson RHS, Hopkinson BR, Makin GS. Randomized trial of intra-arterial recombinant tissue plasminogen activator, intravenous recombinant tissue plasminogen activator and intra-arterial streptokinase in peripheral arterial thrombolysis. Brit J Surg 1991; 78: 988-995.

3. Meyerovitz MF, Goldhaber SZ, Reagan K, Polak JF, Kandarpa K, Grassi CJ, Donovan BC, Bettmann MA, Harrington DP. Recombinant tissue-type plasminogen activator versus urokinase in peripheral arterial and graft occusions: a randomized trial. Radiology 1990; 175: 75-78.

4. Ouriel K, Veith FJ, Sasahara AA, for the TOPAS investigators. Thrombolysis or peripheral arterial surgery: Phase I results. J Vasc Surg 1996; 23: 64-75.

5. Nilsson L, Albrechtsson U, Jonung T, Ribbe E, Thorvinger B, Thôrne J, Astedt B, Norgren L. Surgical treatment versus thrombolysis in acute arterial occlusion: a randomized controlled study. Eur J Vasc Surg 1992; 6: 189193

6. Ouriel K, Shortell CK, De Weese JA, Green RM, Francis CW, Azodo MVU, Guttierrez DH, Manzione JV, Co C, Marder JV. A comparison of thrombolytic therapy with operative vascularization in the initial treatment of acute peripheral arterial ischemia. J. Vasc. Surg. 1994; 19: 1021-1030.

7. The STILE Investigators. Results of a prospective randomized trial evaluating surgery versus thrombolysis for ischemia of the lower extremity. The STILE trial. Ann Surg 1994; 220: 251-268.

8. Ouriel K, Veith FJ, Sasahara AA for the Thrombolysis or Peripheral Arterial Surgery (TOPAS) Investigators. A comparison of recombinant urokinase with vascular surgery as initial treatment for acute arterial occlusion of the legs. N Engl J Med 1998; 338: 11051111.

9. Palfrayman SJ, Booth A, Michaels JA. A systematic review of intra-arterial thrombolytic therapy for lower-limb ischaemia. Eur J Vasc Endovasc Surg 2000; 19: 143-157.

10. Working Party on Thrombolysis in the Management of Limb Ischemia. Thrombolysis in the management of limb peripheral arterial occlusion - a consensus document. Am J Cardiol 1998; 81: 207-218.

11. Ouriel K, Kendarpa K, Schuerr DM, Hultquist M, Hodkinson G, Wallin B. Prourokinase versus urokinase for recanalization of peripheral occlusions, safety and efficacy: the PURPOSE trial. J Vasc Interv Radiol 1999; 10: 10831091.

12. Vanderschueren S, Stockx L, Wilms G, Lacroix H, Verhaeghe R, Vermylen J, Collen D. Thrombolytic therapy of peripheral arterial occlusion with recombinant staphylokinase. Circulation 1995; 92: 2050-2057.

13. Heymans S, Vanderschueren S, Verhaeghe R, Stockx L, Lacroix H, Nevelsteen A, Laroche Y, Collen D. Outcome and one year follow-up of intra-arterial staphylokinase in 191 patients with peripheral arterial occlusion. Thromb Haemost 2000; 83: 666-671.

14. Davidian MM, Powell A, Benenati JF, Katzen BT, Becker GJ, Zemel G. Initial results of reteplase in the treatment of acute lower extremity arterial occlusions. . J Vasc Interv Radiol 2000; 11: 289-294.

15. Ouriel K, Katzen B, Mewissen M, Flick P, Clair DG, Benenati J, McNamara TO, Gibbens D. Reteplase in the treatment of peripheral arterial and venous occlusions: a pilot study. J Vasc Interv Radiol 2000; 11: 849-854.

16. Ouriel K, Veith F. Acute lower limb ischemia: determinants of outcome. Surgery 1998; 124: 336-342.

17. Duda SH, Tepe G, Luz O, Ouriel K, Dietz K, Hahan U, Pereira P, Marsalek P, Ziemer G, Erley CM, Claussen CD. Peripheral artery occlusion: treatment with abciximab plus urokinase versus urokinase alone - a randomized pilot trial (the PROMPT study). Radiology 2001; 221: 689-696.

18. Drescher P, Crain MR, Rilling WS. Initial experience with the combination of reteplase and abciximab for thrombolytic therapy in peripheral arterial occlusive disease: a pilot study. J Vasc Interv Radiol 2002; 13: 37-43

19. Marder VJ, Landskroner K, Novokhatny V, Zimmerman TP, Kong M, Kanouse JJ, Jesmok G. Plasmin induces local thrombolysis without causing hemorrhage: a comparison with tissue plasminogen activator in the rabbit. Thromb Haemost 2001; 86: 739-745.

20. Collen D. Revival of plasmin as a therapeutic agent? Thromb Haemost 2001; 86: 731-2.

21. Kasirajan K, Haskal ZJ, Ouriel K. The use of mechanical thrombectomy devices in the management of acute peripheral arterial occlusive disease. J Vasc Interv Radiol 2001; 12: 405411.

22. Francis CW, Suchkova VN. Ultrasound and thrombolysis. Vascular Medicine 2001; 6: 181187. 